\title{
Urethral cytology in spinal cord injury patients performing intermittent catheterisation
}

\author{
S Vaidyanathan MS MCh PhD,${ }^{1}$ B M Soni MB MS, ${ }^{2} \mathrm{~S}$ Dundas MB MRCPath, ${ }^{3}$ \\ K R Krishnan MB FRCS ${ }^{4}$ \\ ${ }^{1}$ Registrar, ${ }^{2}$ Associate Specialist, ${ }^{4}$ Consultant in Spinal Injuries and Director, Mersey \\ Regional Spinal Injuries Centre, Town Lane, Kew, Southport PR8 6PN, England; \\ ${ }^{3}$ Consultant Histopathologist, Southport General Infirmary, Scarisbrick New Road, \\ Southport PR8 6PH, England.
}

Local reactions of the urethral wall are known to occur by repeated introduction of a catheter in the urethra. Urethritis was found in $2-19 \%$ of patients practising intermittent catheterisation. Although the use of catheters of smaller size and the liberal use of lubricants may prevent urethral irritation and trauma, it was postulated that hydrophilic catheters (LoFric, Astra Tech Ltd, Stroud, England) induce significantly less trauma than PVC catheters because of the binding of the water molecules to the catheter surface which consists of polyvinylpyrrolidone and sodium chloride. Although urethritis and urethral stricture may represent one end of the spectrum of repeated urethral trauma, minor degrees of inflammation need to be quantitatively determined while assessing two different catheters for intermittent catheterisation. The degree of urethral inflammation in patients practising intermittent catheterisation was studied by urethral cytology and staining the smear by Papanicolaou's method. The number of neutrophil polymorphs and epithelial cells in three random high power fields in the urethral smear was counted and the percentage ratio of polymorphs to epithelial cells was calculated. Group 1 comprised 14 patients practising intermittent catheterisation with a PVC catheter and group 2 comprised 17 patients performing intermittent catheterisation with a LoFric catheter. There was no significant difference between the two groups as regards the age, diagnosis, size of the catheter used for intermittent catheterisation and the number of times that they performed catheterisation during a 24 hour period. Urethral cytology revealed a percentage (mean ratio) ratio of polymorphs to epithelial cells of 66 in group 1 and 0.04 in group 2. $(<0.0005)$. Urethral cytology also revealed a significantly greater number of bacteria in group 1 as compared to group 2 $(p<0.01)$. In conclusion, use of a LoFric catheter for intermittent catheterisation was associated with significantly lesser degree of urethral inflammatory response when compared to the use of a PVC catheter.

Keywords: urethral cytology; urethral intermittent catheterisation; spinal cord
injury.

\section{Introduction}

Lapides et al reported the first experience with clean intermittent catheterisation in 1972. ${ }^{1}$ Repeated catheterisation might affect

Correspondence: Mr B M Soni MB MS, Spinal Injuries Centre, District General Hospital, Town Lane, Southport PR8 6PN, UK. the urethral wall. Labat et al found modifications of the urethral wall especially in male patients having clean intermittent self catheterisation where this had been performed for longer than 1 year. ${ }^{2}$ Urethritis was found in $2 \%$ of patients by Lapides et al, ${ }^{3} 19 \%$ by Labat et $a l^{2}$ and $11 \%$ by Wyandale et al. ${ }^{4}$ Wyndaele \& Maes ${ }^{5}$ observed in a retrospective study that seven of 
33 male patients performing clean intermittent catheterisation developed a urethral stricture, most complications occurring after 5 years of clean intermittent self catheterisation. These studies suggest that local reactions of the urethral wall induced by repeated introduction of a catheter seem to occur. Almost all reports in the literature describe the use of small catheters (14-16 Fr) and the liberal use of lubricants by male patients. This measure alone does not seem to prevent urethral irritation and trauma in the long term.

Recently a hydrophilic low friction catheter has been introduced for intermittent catheterisation. When compared with ordinary plastic catheters used with lubrication, the friction of these catheters is $90-95 \%$ lower. The reason is that the surface of the low friction catheter consists of polyvinylpyrrolidone, which absorbs water by binding the water molecules to the catheter surface. This provides a lubricating layer that does not come off when using the low friction catheter, which is normally not the case when using lubricating gels with ordinary catheters.

Urethritis and urethral stricture formation represent severe degrees of urethral trauma and their sequelae. It is desirable to detect lesser degrees of urethral trauma so that appropriate corrective steps can be undertaken before urethral stricture develops. Catheter induced inflammatory response has been studied by Talja et al in $1.990 .^{6}$ The urethral inflammatory reaction was assessed from cytological urethral swab specimens. These authors made an interesting observation that neither the age of the patients nor the duration of catheterisation had any effect on the inflammatory reaction.

We proposed to apply the same technique of urethral cytology to assess the inflammatory response to different types of catheters used by patients for intermittent catheterisation. A group of patients on long term indwelling urethral catheter drainage were also included in the study as the urethral inflammatory response shown by these patients on indwelling catheter drainage will provide the yardstick to compare the inflammatory response produced by repeated catheterisation in patients on the intermittent catheterisation regime.

\section{Methods and material}

Patients practising intermittent urethral catheterisation were the subjects of this study. The exclusion criteria were: (1) a history of urethral bleeding during or after catheterisation, (2) acute urinary tract infection manifested by fever, chills, passage of foul smelling urine, dysreflexic episodes, urethral discharge or epidydymitis, (3) concurrent intake of antibiotics, (4) using different types of catheters for catheterisation and (5) using different sizes of catheters for catheterisation. The inclusion criteria were that the patient should be (1) using the same type and size catheter for intermittent catheterisation and (2) willing to provide a urethral smear for cytology and to give verbal consent for the same.

\section{Technique of urethral cytology}

A urethral cytology sample was taken from the urethra $3 \mathrm{~cm}$ proximal to the external urethral meatus with a sterile wool and cotton swab. (Cytoswab, Cell Path PLC, PO Box 101, Hemel Hempstead, Herts HP3 8 HQ). The swab was then smeared onto a clean slide and the smear was immediately fixed in methyl alcohol. The urethral cytology samples were always taken either by the specified nurse or by the specified doctor. Prior to the commencement of the study, both these members of the team took urethral smears from patients and these smears were stained and examined for the presence of an adequate number of cells. Once it was established that satisfactory urethral cytology specimens can be obtained uniformly by the specified nurse and the doctor, the study was begun. All the smears which had been fixed were later stained together by Palpanicolaou's method. All urethral cytology slides were examined by a consultant cytopathologist (SD) who was unaware of the clinical details of the patient.

Assessment of urethral cytology specimens Each slide of urethral cytology was examined for (1) cellularity, (2) presence of 
bacteria, (3) the number of epithelial cells and neutrophil polymorphs in three random high power fields. Percentage ratio of polymorphs to epithelial cells was calculated as follows:-

Total number of polymorphs in three high power fields

Total number of epithelial cells in three high power fields

The presence of bacteria was subjectively assessed in an ordinal scale of $0-3$.

\section{Clinical profile of patients}

The patients, as and when they attended the outpatient clinic or the ward for either routine review or for some other problem between July '93 and October '93, were enrolled in the study provided they satisfied the entry criteria (see above). The patient's age, diagnosis, type and size of catheter used for intermittent catheterisation, frequency of catheterisation per 24 hours and the time period during which the patient had been performing intermittent catheterisation were noted. Immediately after the patient had performed intermittent catheterisation, urethral cytology specimen was obtained.

We also studied a group of 11 patients who were on indwelling urethral catheter drainage and who attended the clinic for a change of urethral catheter. Before inserting a new Foley catheter, a urethral cytology swab was taken from these patients who had indwelling urethral catheter drainage.

\section{Results}

The patients practising intermittent catheterisation fell into two groups; group 1 comprising 14 patients using a PVC catheter and group 2 comprising 17 patients using a LoFric catheter. The clinical profile of these two groups of patients are given in Tables I and II respectively. The clinical profile of the 11 patients who were on indwelling urethral catheter drainage (group 3 ) is given in Table III.
Age

The mean age of patients using a PVC catheter was 32.15 years, whereas the mean age of patients using a LoFric catheter was 45.41 years. Two sample $t$ tests revealed no significant difference between the two groups.

\section{Diagnosis}

There were eight paraplegic and four tetraplegic patients in group 1, besides two patients with spina bifida, whereas in group 2 there were 14 paraplegic and one tetraplegic patient, besides one patient with spina bifida and one who had multiple sclerosis. There was no significant difference between the two groups.

\section{Catheter size}

Most of the patients were using $12 \mathrm{Fr}$ catheter for intermittent catheterisation, although a few used 8,10 or $14 \mathrm{Fr}$ catheter. $\chi^{2}$ test revealed no significant difference between the two groups as regards catheter size.

\section{Duration of catheterisation}

The duration of intermittent catheterisation varied considerably; the median for group 1 patients who were using a PVC catheter was 24 days, whereas for the LoFric group (group 2) the median was 151 days. Wilcoxan signed rank test revealed a significant difference between the two groups $(p=0.0077)$. Thus, patients in the LoFric catheter group were in fact practising intermittent catheterisation for a significantly longer period and were thus exposed to repeated urethral trauma for a longer duration.

\section{Frequency of catheterisation}

The median for group 1 was 5, whereas for group 2 the median was 4.5 . The Wilcoxan signed rank test revealed no significant difference between the two groups as regards the frequency of catheterisation. 
Table I Clinical profile of patients using a PVC Nelaton catheter for intermittent catheterisation

\begin{tabular}{|c|c|c|c|c|c|c|c|c|}
\hline Patient & Sex & $\begin{array}{c}\text { Age } \\
\text { (years) }\end{array}$ & Diagnosis & $\begin{array}{l}\text { Catheter } \\
\text { size }\end{array}$ & $\begin{array}{l}\text { Duration of } \\
\text { catheterisation }\end{array}$ & $\begin{array}{l}\text { Frequency of } \\
\text { catheterisation } \\
\text { (per day) }\end{array}$ & Bacteria & $\begin{array}{l}\text { Polymorph to } \\
\text { epithelial } \\
\text { cells ratio }\end{array}$ \\
\hline 1 & $\mathrm{M}$ & 50 & Incomplete paraplegia & 12 & 3 months & 3 & 0 & 0 \\
\hline 2 & $\mathrm{~F}$ & 52 & Paraplegia & 12 & 24 days & 5 & 0 & 9.8 \\
\hline 3 & $\mathrm{~F}$ & 27 & Spina bifida & 10 & 11 years & 5 & 1 & 0.5 \\
\hline 4 & $\mathrm{M}$ & 32 & Traumatic paraplegia & 10 & 1 week & 5 & 0 & 0 \\
\hline 5 & M & 18 & Spina bifida & 10 & 18 months & 6 & 1 & 88.9 \\
\hline 6 & $\mathrm{~F}$ & 27 & Traumatic tetraplegia & 12 & l year & 5 & 1 & 23.4 \\
\hline 7 & $\mathrm{M}$ & 31 & Traumatic paraplegia & 12 & 2 months & 5 & 1 & 2.2 \\
\hline 8 & $\mathrm{M}$ & 34 & Traumatic paraplegia & 12 & 4 days & 3 & 0 & 0 \\
\hline 9 & $\mathrm{~F}$ & 25 & Incomplete paraplegia & 12 & 1 week & 2 & 0 & 0 \\
\hline 10 & $\mathrm{M}$ & 4 & Traumatic tetraplegia & 8 & 12 days & 2 & 0 & 1.7 \\
\hline 11 & M & 27 & Incomplete paraplegia traumatic & 12 & 5 weeks & 4 & 1 & 0 \\
\hline 12 & $\mathrm{M}$ & 56 & Incomplete tetraplegia & 12 & 1 month & 5 & 0 & 15.7 \\
\hline 13 & $\mathrm{~F}$ & 14 & Traumatic tetraplegia & 12 & 6 weeks & 6 & 2 & 27.9 \\
\hline 14 & $\mathrm{~F}$ & 71 & Incomplete paraplegia traumatic & 12 & 2 days & 3 & 3 & 754 \\
\hline
\end{tabular}


Table II Clinical profile of patients using a LoFric Nelaton catheter for intermittent catheterisation

\begin{tabular}{|c|c|c|c|c|c|c|c|c|}
\hline Patient & Sex & $\begin{array}{c}\text { Age } \\
\text { (years) }\end{array}$ & Diagnosis & $\begin{array}{l}\text { Catheter } \\
\text { size }\end{array}$ & $\begin{array}{l}\text { Duration of } \\
\text { catheterisation }\end{array}$ & $\begin{array}{c}\text { Frequency of } \\
\text { catheterisation } \\
\text { (per day) }\end{array}$ & Bacteria & $\begin{array}{l}\text { Polymorph to } \\
\text { epithelial } \\
\text { cells ratio }\end{array}$ \\
\hline 1 & M & 72 & Traumatic paraplegia & 12 & 6 weeks & 3 & 0 & 0 \\
\hline 2 & M & 35 & Traumatic paraplegia & 12 & 15 months & 5 & 0 & 0 \\
\hline 3 & M & 28 & Thoracic paraplegia & 12 & 1 year & 5 & 0 & 0 \\
\hline 4 & M & 33 & Multiple sclerosis & 12 & 2 weeks & 5 & 0 & 0 \\
\hline 5 & M & 46 & Traumatic paraplegia & 12 & 18 months & 3 & 0 & 0 \\
\hline 6 & M & 35 & Traumatic paraplegia & 12 & 1 year & 3 & 1 & 0 \\
\hline 7 & M & 67 & Incomplete paraplegia & 12 & 6 weeks & 4 & 1 & 0.7 \\
\hline 8 & M & 64 & Traumatic paraplegia & 10 & 1 month & 5 & 0 & 0 \\
\hline 9 & M & 53 & Transverse myelitis & 12 & 6 months & 10 & 0 & 0 \\
\hline 10 & M & 26 & Traumatic tetraplegia & 14 & 6 months & 3 & 0 & 0 \\
\hline 11 & M & 42 & Traumatic paraplegia & 12 & 1 month & 1 & 0 & 0 \\
\hline 12 & $\mathrm{M}$ & 24 & Traumatic paraplegia & 12 & 6 months & 4 & 0 & 0 \\
\hline 13 & $\mathrm{M}$ & 23 & Spina bifida & 12 & 6 weeks & $4-5$ & 0 & 0 \\
\hline 14 & $\mathrm{M}$ & 45 & Transverse myelitis & 12 & 6 months & $4-5$ & 0 & 0 \\
\hline 15 & $\mathrm{M}$ & 41 & Traumatic paraplegia & 12 & 3 months & 2 & 0 & 0 \\
\hline 16 & M & 74 & Traumatic paraplegia & 12 & 3 months & 5 & 0 & 0 \\
\hline 17 & M & 64 & Paraplegia & 12 & 6 months & 5 & 0 & 0 \\
\hline
\end{tabular}




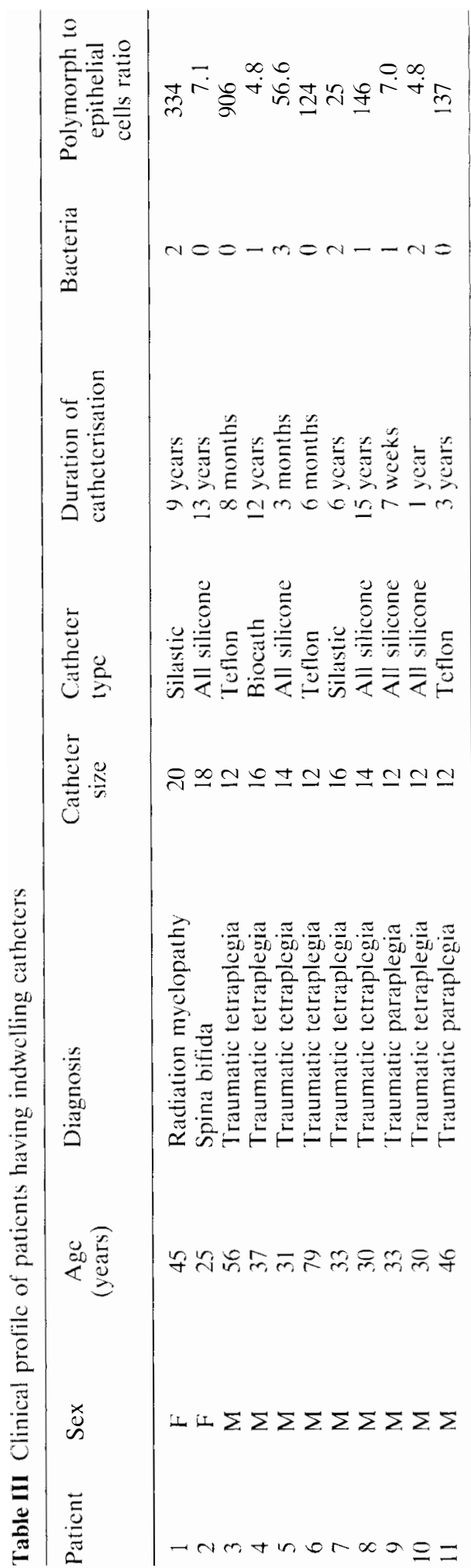

\section{Analysis of urethral cytology}

The polymorphs to epithelial cell ratio in the urethral cytology of the three groups is depicted in Figure 1. As expected, the polymorphs to epithelial cell ratio was highest in those patients with indwelling urethral catheter drainage (mean: 159.3); much less in those practising intermittent catheterisation with PVC catheters (mean: 66) and least in those using a LoFric catheter for intermittent catheterisation (mean 0.04). Wilcoxon signed rank test revealed significant difference between groups 1 and 3 $(p=0.0254)$, between groups 2 and 3 $(p<0.0001)$ and also between groups 1 and $2(p=0.0005)$. Urethral cytology of representative patients of group 1, group 2 and group 3 are shown in Figures 2, 3 and 4 respectively. Whereas very few polymorphs are seen in the urethral cytology smear of the patient practising intermittent catheterisation with a LoFric catheter (Fig 3), the field is studded with polymorphs in the patient with indwelling urethral catheter drainage (Fig 4) and the urethral inflammatory response in the patient practising intermittent catheterisation with a PVC catheter

Percentage ratio of polymorph to epithelial cells

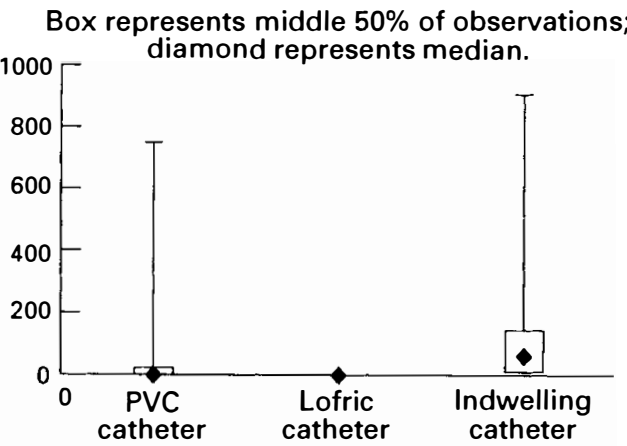

Figure 1 Neutrophil polymorphs to epithelial cell ratio in the urethral cytology of spinal injury patients using PVC catheters for intermittent catheterisation (group 1), in patients using hydrophilic catheters (LoFric) for intermittent catheterisation (group 2), and in those with indwelling urethral catheter drainage (group 3). Least inflammatory response is seen in those patients using hydrophilic catheters for intermittent catheterisation. 


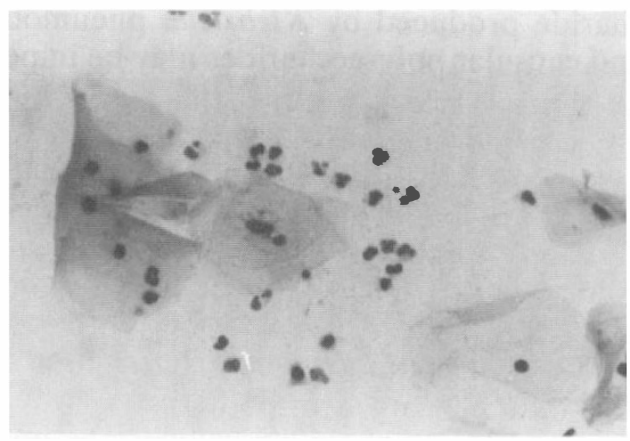

Figure 2 Urethral cytology of patient 6 who has been using a PVC catheter for intermittent catheterisation. Moderate degree of neutrophil polymorph response is seen. The polymorphs to epithelial cell percentage ratio was 23.4.

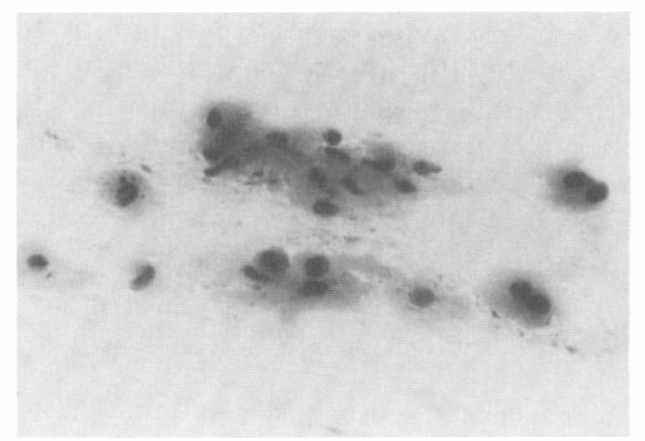

Figure 3 Urethral cytology of patient 7 who has been using LoFric catheters for intermittent catheterisation. He is the only patient amongst those using hydrophilic catheters to exhibit any inflammatory response. The polymorphs to epithelial cell percentage ratio was 0.7 .

is moderate (Fig 2). This clearly shows the superiority of intermittent catheterisation over indwelling urethral catheter drainage, in that the former produces a significantly lesser degree of urethral inflammation as studied by urethral cytology. Even in those practising intermittent catheterisation, hydrophilic catheter with PVP coating (LoFric catheter) produced a lesser degree of urethral inflammation as compared to the use of PVC catheter without the hydrophilic coating.

\section{Bacteria}

The median for group 1 was 0.5 , whereas the median for group 2 was 0 . The Mann-
Whitney $U$ test revealed a significant difference between the two groups $(p=0.01)$. Thus significantly greater numbers of bacteria were seen in those practising intermittent catheterisation with a PVC catheter as compared to those using a LoFric catheter.

\section{Discussion}

Hellstrom et $\mathrm{al}^{7}$ carried out a prospective study on the efficacy and safety of clean intermittent catheterisation in 15 females and 26 males, the mean follow up time being 40 months. All of them used a self-lubricating hydrophilic catheter. There were no urethral complications suggesting that the self-lubricating hydrophilic catheters may be less traumatic than those used previously. This finding is in contrast to the observations of Wyndaele \& Maes $^{5}$ who noted urethral meatitis in two, urethral meatal stenosis in one, urethral stricture in seven and urethral false passage in three, amongst 75 patients who performed clean intermittent self catheterisation for a mean of 7 years. The present study has clearly shown that urethral inflammatory response to repeated urethral catheterisation with a selflubricating hydrophilic catheter is significantly less as compared to the urethral inflammatory response which was observed in those patients performing intermittent catheterisation with a PVC catheter (Fig 1). Thus, self-lubricating hydrophilic catheters which produce $90-95 \%$ less amount of

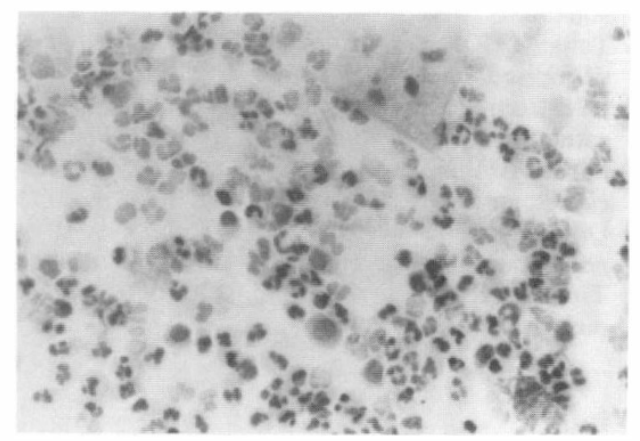

Figure 4 Urethral cytology of patient 11 who has been on indwelling urethral catheter drainage. Innumerable neutrophil polymorphs are seen with the polymorphs to epithelial cell percentage ratio being 906 . 
friction are shown to produce less urethral inflammation and may be better suited for an intermittent catheterisation regimen.

However, urethral cytology performed during a prospective, controlled clinical trial on the use of a self-lubricating hydrophilic catheter and a PVC catheter used with lubricating gel will show how soon the patients using the PVC catheter develop the florid urethral inflammatory response and whether these inflammatory changes in the urethra subside on changing over to the self-lubricating hydrophilic catheter.

Hellstrom et al ${ }^{7}$ noted that $73 \%$ of the 30 patients using the self-lubricating hydrophilic catheter for intermittent catheterisation experienced bacteruria during the procedure and in their study most episodes of bacteruria were symptomatic. Recently, the use of salicylic acid to coat urinary or other medical devices has provided a novel approach in attempting to decrease the incidence of infection. ${ }^{8}$ Domenico et $a l^{9}$ demonstrated that sodium salicylate reduced the amount of capsular polysac- charide produced by Klebsiella pneumonia and capsular polysaccharides may be important in the attachment of bacteria to polymers. When catheters were pretreated both with tridodecylmethylammonium (TDMAC) and salicylic acid (NSAID), there was a marked (94-99\%) inhibition of adherence of $E$. Coli with the treated catheters. $^{8}$

TDMAC has previously been used to provide a slow release system with antibiotic- and heparin-coated polymers. The polar part of the TDMAC molecule binds ionically to the antibiotic or NSAID, and the rest of the molecule binds to the catheter surface. As much as $60 \%$ of the compound remains bound for 2 weeks. ${ }^{10}$ Thus, in future, the self-lubricating hydrophilic catheters coated with NSAID or antibiotic may be the catheter of choice for intermittent catheterisation as it will not only produce minimal friction, and hence minimal urethral inflammatory response, but also decrease the incidence of catheter-related infection.

\section{References}

1 Lapides J, Diokno AC, Silber S, Lowe BS (1972) Clean intermittent self catheterisation in the treatment of urinary tract disease. J Urol 107: 458.

2 Labat JJ, Perrouin-Verbe B, Lanoiselee JM, Mathe JF, Buzelin JM (1985) L'autosondage intermittent propre dans la rééducation des blesses medullaires et de la queue de cheval I. Ann Readapt Med Phys 28: 111.

3 Lapides J, Diokno AC, Gould FR, Lowe BS (1976) Further observations on self-catheterisation. J Urol 116: 169.

4 Wyndaele JJ, Vosterlinck W, DeSy W (1980) Clean intermittent self-catheterisation in the chronic management of the neurogenic bladder. Eur Urol 6: 107.

5 Wyndaele JJ, Maes D (1990) Clean intermittent self-catheterisation-A 12 year follow-up. J Urol 143: 906-908.

6 Talja M, Korpela A, Jarvi K (1990) Comparison of urethral reaction to full silicone, hydrogen-coated and siliconised latex catheters. Br J Urol 66: 652-7.

7 Hellstrom P, Tammela T, Lukkarinen O, Kontturi M (1991) Efficacy and safety of clean intermittent catheterisation in adults. Eur Urol 20: 117-121.

8 Farber BF, Wolff AG (1993) The use of salicylic acid to prevent the adherence of Escherichia coli to silastic catheters. J Urol 149: 667-670.

9 Domenico P. Schwartz S, Cunha BA (1989) Reduction of capsular polysaccharide production in Klebsiella pneumoniae by sodium salicylate. Infect Immun 57: 3778-3782.

10 Truoskin SZ, Donetz AD, Baxter J, Harvey RA, Greco RS (1987) Infection resistant continuous peritoneal dialysis catheters. Nephron 46: 263. 